\title{
Politique
}

Politique

\section{John Kenneth Galbraith, Anatomie du pouvoir, Paris, Seuil, 1985, 190 p.}

\section{Vincent Lemieux}

Numéro 8, automne 1985

Innovations et politiques technologiques

URI : https://id.erudit.org/iderudit/040510ar

DOI : https://doi.org/10.7202/040510ar

Aller au sommaire du numéro

\section{Éditeur(s)}

Société québécoise de science politique

ISSN

0711-608X (imprimé)

1918-6584 (numérique)

Découvrir la revue

Citer ce compte rendu

Lemieux, V. (1985). Compte rendu de [John Kenneth Galbraith, Anatomie du pouvoir, Paris, Seuil, 1985, 190 p.] Politique, (8), 174-176.

https://doi.org/10.7202/040510ar d'utilisation que vous pouvez consulter en ligne.

https://apropos.erudit.org/fr/usagers/politique-dutilisation/ 
John Kenneth Galbraith, Anatomie du pouvoir,Paris, Seuil, 1985, $190 \mathrm{pp}$.

Le but du livre est présenté, de façon imagée à la fin de l'avant-propos: "J'ai voulu, écrit l'auteur, faire en sorte que, son habillage de chair lui ayant été arraché, l'anatomie du pouvoir apparaisse en pleine lumière» (p. 9).

Le pouvoir, selon Galbraith, est fait de trois instruments: la dissuasion, la rétribution et la persuasion; et de trois sources: la personnalité, la propriété et l'organisation. 
Les premiers chapitres présentent les trois instruments et les trois sources. Viennent ensuite deux chapitres sur la dialectique du pouvoir, qui montrent que le pouvoir engendre des contrepouvoirs et qu'il fait l'objet de réglementation. Les chapitres suivants font l'histoire du pouvoir, depuis le monde précapitaliste jusqu'à aujourd'hui. Selon Galbraith, l'État est devenu une organisation dominante qui cumule les trois instruments et les trois sources du pouvoir. De cet État, l'establishment militaire est de loin l'organe le plus puissant. L'ouvrage se termine par un chapitre sur le pouvoir de la religion et de la presse, suivi d'une conclusion sur la concentration et la diffusion du pouvoir.

La catégorisation en trois instruments et en trois sources permet de donner un traitement relativement simple du pouvoir à travers l'histoire. Dans le passé, et encore aujourd'hui, dans les sociétés à faibles ressources, le pouvoir est souvent personnel et s'exerce selon le mode de la dissuasion. Dans nos sociétés développées le principal instrument du pouvoir est la persuasion et sa source la plus fréquente est l'organisation. L'âge d'or de la rétribution et de la propriété se situe au moment où le capitalisme est à son apogée.

La pensée de Galbraith est, bien sûr, plus subtile que le résumé qui vient d'en être donné, mais elle apparaît souvent simplificatrice et teintée d'évolutionnisme. La société américaine est posée, explicitement ou implicitement, comme terme de cette évolution. D'où certaines affirmations étonnantes, comme celleci, par exemple: "L'organisation est une ressource à laquelle tout le monde peut à tout instant avoir recours» (p. 168). Même pour les États-Unis, cette généralisation est très contestable.

L'insistance est mise de façon excessive sur les phénomènes de symétrie, entre le pouvoir interne et le pouvoir externe d'une organisation, ou encore entre les sources et les instruments d'un pouvoir et ceux du contre-pouvoir qui le combat. Une organisation qui cherche à exercer de la dissuasion à l'extérieur d'elle-même 
reposerait sur de la dissuasion interne, et ainsi de suite. $\grave{A}$ un pouvoir qui repose sur l'organisation s'opposerait un contre-pouvoir qui se donnerait le même instrument. Cela permet à l'auteur des généralisations élégantes, mais qui sont loin du concret. Dans les négociations entre patrons et syndicats ou encore entre nations, tous les instruments et toutes les sources du pouvoir sont employés, même si à certains moments, il est vrai, des symétries se dessinent entre les instruments ou les sources proéminentes du pouvoir.

Une critique plus fondamentale peut être faite au livre de Galbraith comme d'ailleurs à la plupart des travaux sur le pouvoir. Tout au long de l'ouvrage, à l'exception des chapitres 8 et 9 , le pouvoir est présenté comme un attribut des individus et des groupes. Les deux chapitres qui font exception montrent que le pouvoir appelle des contre-pouvoirs et que ces pouvoirs opposés sont réglementés. Ces chapitres ne servent que de transition entre l'approche conceptuelle et l'approche plus historique du pouvoir, alors qu'une véritable science sociale des relations de pouvoir doit partir d'une vue systémique. Ce n'est que dans un ensemble de relations, qui ont leurs règles et plus fondamentalement leurs lois, que l'exercice du pouvoir par un individu ou par un groupe prend un sens. Les relations ainsi formées ne peuvent être comprises que dans de vastes systèmes, qui sont structurés de diverses façons. Il y a des structurations hiérarchiques ou stratarchiques, d'autres qui sont plus égalitaires et d'autres enfin qui ont un caractère anarchique.

L'anatomie, nous dit-on, est l'étude scientifique de la structure et de la forme des êtres organisés ainsi que des rapports entre leurs différents organes. L'ouvrage de Galbraith n'est pas cela. Il s'en tient à la classification et à l'application historique de certains éléments du pouvoir, sans en cerner vraiment les rapports, la forme et la structure.

Vincent Lemieux Université Laval 